\title{
Circulating endothelin in acute ischaemic syndromes
}

\author{
Simon G Ray, John J McMurray, James J Morton, Henry J Dargie
}

Department of Cardiology and the MRC Pressure Unit, Western Infirmary, Glasgow, UK S G Ray

J J McMurray

J J Morton

H J Dargie

Correspondence to Dr S G Ray, Department of Cardiology, Freeman Hospital, Freeman Road, Newcastle on Tyne NE7 7DN

Accepted for publication 8 October 1991

\begin{abstract}
Background-Endothelin is an extremely potent vasoconstrictor that may have a role in the pathogenesis of acute myocardial ischaemia. Atrial natriuretic factor is an endogenous antagonist of endothelin. To find the pattern and possible importance of circulating endothelin in ischaemic heart disease, concentrations in normal controls and those in patients with stable and unstable angina, acute myocardial infarction, and chronic cardiac failure were compared. The relation between circulating concentrations of endothelin and atrial natriuretic factor in the aftermath of myocardial infarction was also examined.
\end{abstract}

Methods-Eighteen patients with acute myocardial infarction, 10 with unstable angina, 10 with stable angina, 12 with chronic cardiac failure, and 10 normal controls were studied. Endothelin concentration was measured in venous plasma by radioimmunoassay. In patients with acute myocardial infarction simultaneous concentrations of endothelin and atrial natriuretic factor were measured on admission and at one, four, and 24 hours.

Results-Mean concentrations (SEM) of endothelin were $5.72(0.19) \mathrm{fmol} / \mathrm{ml}$ in controls, $6.56(0.48) \mathrm{fmol} / \mathrm{ml}$ in stable angina, $6.41(0.48) \mathrm{fmol} / \mathrm{ml}$ in unstable angina, and $13.83(0.95) \mathrm{fmol} / \mathrm{ml}$ in chronic cardiac failure. In acute myocardial infarction concentrations were $\mathbf{8 \cdot 8 1}$ (0.69) $\mathrm{fmol} / \mathrm{ml}$ on admission, 11.85 (1.02) fmol $/ \mathrm{ml}$ at one hour, $11 \cdot 88(1 \cdot 10) \mathrm{fmol} / \mathrm{ml}$ at four hours, and $7 \cdot 30(0 \cdot 49) \mathrm{fmol} / \mathrm{ml}$ at 24 hours. Concentrations of atrial natriuretic factor at the same times were 68.1 (13.1) $\mathrm{pg} / \mathrm{ml}, 8 \cdot 4(1 \cdot 5) \mathrm{pg} / \mathrm{ml}, 24 \cdot 4$ (4.1) $\mathrm{pg} /$ $\mathrm{ml}$, and $42 \cdot 0(6 \cdot 9) \mathrm{pg} / \mathrm{ml}$.

Conclusions-Plasma endothelin is raised in chronic heart failure and in the aftermath of acute myocardial infarction but not in stable or unstable angina. After myocardial infarction endothelin concentrations are raised whereas concentrations of atrial natriuretic factor are relatively low. The role of endothelin in the pathogenesis of acute myocardial infarction and its interactions with other humoral factors require further investigation.

The endothelins are a family of three isopeptides that are extremely potent vasoconstrictors both in vivo and in vitro. ${ }^{12}$ The development of sensitive assays has allowed the measurement of the low concentrations of endothelin circulating in plasma, and raised concentrations have been shown in a number of conditions including renal failure, ${ }^{3}$ subarachnoid haemorrhage, ${ }^{4}$ and after major surgery, ${ }^{5}$ cardiogenic shock, ${ }^{6}$ and acute myocardial infarction. ${ }^{7-9}$ Little is known about the release of endothelin in ischaemic heart disease although left ventricular dysfunction, damage to the endothelium, and activation of coagulation and platelets have been suggested as possible stimuli. ${ }^{79}$ Little is known, furthermore, of the relation between endothelin concentrations and those of other vasoactive hormones, particularly atrial natriuretic factor, which antagonises the vasoconstrictive effects of endothelin. ${ }^{10}$

To find the pattern and possible significance of circulating endothelin in ischaemic heart disease we compared concentrations in normal controls with those in patients with stable and unstable angina, acute myocardial infarction, and chronic cardiac failure. We also examined the relation between circulating concentrations of endothelin and atrial natriuretic factor in the aftermath of myocardial infarction.

\section{Patients and methods}

The study group consisted of 10 normal controls, 10 patients with unstable angina, 10 patients with stable angina, 12 patients with established cardiac failure, and 18 patients with acute myocardial infarction. All patients with stable angina had a history of at least three months of exercise induced chest pain, a positive Bruce protocol exercise test and $>50 \%$ stenosis of at least one epicardial artery. Patients with unstable angina had pain at rest lasting for at least $\mathbf{1 0}$ minutes on two or more occasions accompanied by reversible electrocardiographic changes but no rise in cardiac enzymes. These patients were sampled within four hours of the last episode of pain. Patients with established cardiac failure were in New York Heart Association class (NYHAC) III or IV (six with ischaemic cardiomyopathy and six with valvar heart disease). All patients with acute myocardial infarction were admitted within six hours of chest pain with at least $2 \mathrm{~mm}$ ST segment elevation in two or more contiguous electrocardiographic leads. All received 1.5 MU of streptokinase intravenously over 45 minutes. None had had a previous myocardial infarction and all were in Killip class 1. All patients gave informed 
Figure 1 Individual endothelin $(E T-1,2)$ in controls and patients with stable and unstable angina, acute myocardial infarction $(A M I)$, and established cardiac failure. Values for infarct patients are those taken on admission. $\star \star p<0.01$, $\star \star \star p<0.001$ compared with controls. plasma concentrations of

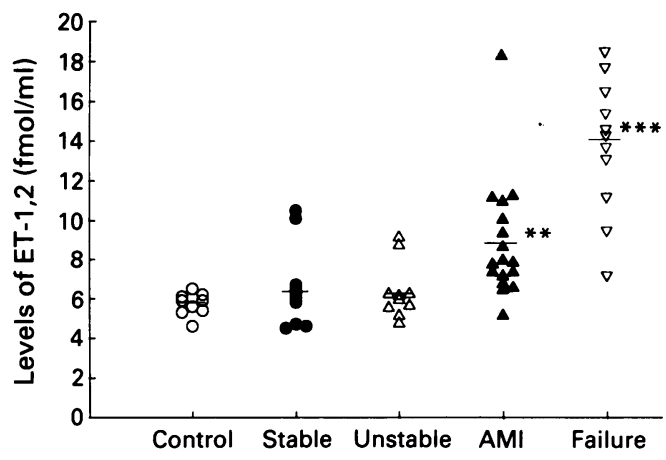

consent and the study was approved by the hospital ethics committee.

All blood samples were taken from an indwelling forearm venous canula after the patient had been resting in a semisupine position for at least 15 minutes. Blood was taken into chilled potassium EDTA tubes on ice and centrifuged at $3000 \mathrm{rpm}$ for 10 minutes at $4^{\circ} \mathrm{C}$ within five minutes of venepuncture. Plasma was stored at $-70^{\circ} \mathrm{C}$ until assay. In patients with myocardial infarction, serial samples were taken on admission, and at one, four, and 24 hours.

Endothelin was assayed using a radioimmunoassay system (Amersham International, Endothelin-1, 2( $\left.{ }^{125} \mathrm{I}\right)$ assay). ${ }^{11}$ The antibody used has $100 \%$ cross reactivity with endothelin-1, 204\% with endothelin-2, $0.024 \%$ with endothelin-3, and $38 \%$ with big endothelin-1. The lower limit of detection is $0.5 \mathrm{fmol} /$ $\mathrm{ml}(1 \mathrm{fmol} / \mathrm{ml}=2.5 \mathrm{pg} / \mathrm{ml})$. Atrial natriuretic factor was assayed using a minor modification of the method of Richards et al, normal range $5-50 \mathrm{pg} / \mathrm{ml}(1 \mathrm{pg} / \mathrm{ml}=0.32 \mathrm{pmol} / \mathrm{l}) .^{12}$

Results are expressed as the mean (SE). Data were analysed by paired or unpaired Student's $t$ tests with the Bonferroni correction for multiple comparisons as appropriate. ${ }^{13}$

\section{Results}

Figure 1 shows that mean concentrations of endothelin in patients with stable angina (6.56 $(0.71) \mathrm{fmol} / \mathrm{ml})$ and unstable angina $(6.41$ $(0.48) \mathrm{fmol} / \mathrm{ml})$ did not differ from normal $(5 \cdot 72(0 \cdot 19) \mathrm{fmol} / \mathrm{ml})$. Mean concentration in patients with cardiac failure $(13.83(0.95) \mathrm{fmol} /$ $\mathrm{ml}$ ) was significantly higher than in the controls

Table Individual plasma endothelin concentrations ( $\mathrm{fmol} / \mathrm{ml}$ ) in patients with myocardial infarction

\begin{tabular}{|c|c|c|c|c|}
\hline & On admission & $1 \mathrm{~h}$ & $4 h$ & $24 h$ \\
\hline & $\begin{array}{r}7.2 \\
7.4 \\
9.4 \\
5 \cdot 2 \\
7.4 \\
6.8 \\
8.7 \\
7.9 \\
11 \cdot 3 \\
10.1 \\
7.8 \\
6.6 \\
11.2 \\
7.8 \\
8.0 \\
6.5 \\
18.3 \\
11.0\end{array}$ & $\begin{array}{r}6 \cdot 8 \\
9 \cdot 0 \\
9 \cdot 8 \\
9 \cdot 1 \\
8 \cdot 1 \\
8 \cdot 0 \\
9 \cdot 1 \\
7 \cdot 1 \\
10 \cdot 9 \\
12 \cdot 7 \\
12 \cdot 3 \\
14 \cdot 1 \\
13 \cdot 0 \\
16 \cdot 0 \\
14 \cdot 7 \\
20 \cdot 3 \\
20 \cdot 4\end{array}$ & \begin{tabular}{r}
$\overline{8}$ \\
\multicolumn{1}{c}{} \\
$\overline{7} \cdot 8$ \\
$8 \cdot 0$ \\
$9 \cdot 7$ \\
$12 \cdot 3$ \\
$10 \cdot 7$ \\
$19 \cdot 4$ \\
$10 \cdot 7$ \\
$11 \cdot 6$ \\
$9 \cdot 6$ \\
$11 \cdot 8$ \\
$14 \cdot 8$ \\
$10 \cdot 1$ \\
$7 \cdot 0$ \\
$23 \cdot 2$ \\
$15 \cdot 2$
\end{tabular} & $\begin{array}{l}5 \cdot 4 \\
6 \cdot 0 \\
7 \cdot 0 \\
6 \cdot 0 \\
9 \cdot 2 \\
8 \cdot 6 \\
6.6 \\
= \\
- \\
\overline{6} \\
8 \cdot 5 \\
6 \cdot 8 \\
5 \cdot 3 \\
6 \cdot 0 \\
8 \cdot 0 \\
12.0\end{array}$ \\
\hline Mean (SEM) & $8.81(0.69)$ & $11.85(1.02)$ & $11 \cdot 88(1 \cdot 10)$ & $7 \cdot 3(0.49)$ \\
\hline
\end{tabular}

( $p<0.001)$. The table shows that for patients with acute myocardial infarction endothelin concentrations were highest at four hours and differed significantly from normal on admission $(\mathrm{p}<0.01)$, at one hour $(\mathrm{p}<0.01)$, and at four hours $(p<0.01)$. The peak concentration of endothelin did not correlate with maximal creatine kinase activity.

Concentrations of atrial natriuretic factor were raised on admission but declined abruptly at one hour, remaining below admission values at 24 hours. In 11 patients with acute myocardial infarction who had simultaneous measurements of both peptides, the fall in concentrations of atrial natriuretic factor coincided with the rise in endothelin (fig 2).

\section{Discussion}

This study shows that plasma endothelin concentrations are raised in the acute phase of myocardial infarction. Salminen et al found a similar pattern of endothelin concentrations in the immediate post infarction period with concentrations peaking at one to four hours and then declining. ${ }^{9}$ Even at 72 hours, however, concentrations were above those in normal controls. Two other groups have described sustained rises in endothelin concentrations for at least three days after infarction though in both cases the highest concentrations were found on admission. ${ }^{78}$ This prolonged increase may be accounted for by the inclusion of patients with more severe degrees of left ventricular failure than in the present study.

The exact role of endothelin in the pathogenesis of myocardial infarction remains undefined. It is undoubtedly an extremely potent vasoconstrictor of both coronary and systemic vessels. This effect could initiate or aggravate acute myocardial ischaemia. Whether circulating concentrations of endothelin in humans reach those sufficient to induce vasoconstriction is uncertain. Infusion of endothelin-1 in humans produces a significant rise in blood pressure at plasma concentrations seven times the preinfusion level ${ }^{14}$ and concentrations of $3 \times 10^{-10} \mathrm{~mol} / 1$ to $3 \times 10^{-}$ ${ }^{9} \mathrm{~mol} / \mathrm{l}$ contract human arteries in vitro. ${ }^{15-17}$ Plasma endothelin concentrations in our infarction patients did not approach these values. This does not rule out a role for endothelin in the pathophysiology of infarction. The primary role of endothelin may be as an autacoid, acting

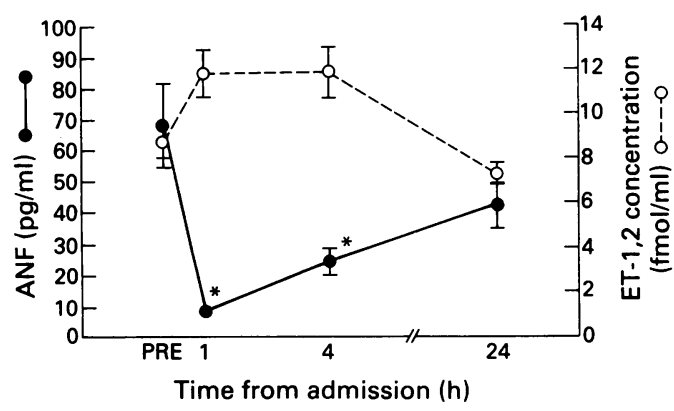

Figure 2 Simultaneous mean (SEM) concentrations of atrial natriuretic factor $(A N F)$, and endothelin ( $E T$ $1,2)$ from admission $(n=11) .{ }^{\star} p<0.05$ compared
with admission. The error bars for $A N F$ at one hour are within the filled circle. 
locally on vascular smooth muscle, with the circulating peptide resulting from spillover into the vascular lumen. ${ }^{18} 19$ If so, then locally released endothelin may have a profound effect on vascular tone despite subthreshold concentrations in plasma. A role for endothelin in evolving myocardial infarction is strongly supported by studies of coronary ligation in the rat. In this model myocardial endothelin content increases after infarction and the extent of ventricular damage is reduced by the use of endothelin antibodies. ${ }^{20}$

Our finding of a negative correlation between concentrations of endothelin and atrial natriuretic factor deserves further comment. A number of authors including ourselves have previously described a fall in circulating atrial natriuretic factor in the immediate aftermath of myocardial infarction..$^{21-23}$ Superfusion of endothelin in atrial cell culture or infusion into intact animals leads to secretion of atrial natriuretic factor. ${ }^{24} 25$ In turn atrial natriuretic factor both decreases the release of endothelin from cultured endothelial cells ${ }^{26}$ and antagonises its vasoconstrictor effects, ${ }^{10}$ thus closing a negative feedback loop and acting as a potential physiological antagonist. The effect of a small rise in circulating endothelin may be magnified by a simultaneous fall in atrial natriuretic factor. Endothelin also interacts synergistically to potentiate noradrenaline induced contractions of coronary arteries and adrenaline increases endothelin release from cultured porcine endothelial cells. ${ }^{27}{ }^{28}$ It is important that changes in endothelin concentrations are considered in the light of other changes in the hormonal milieu that may potentiate its effects.

Several factors may contribute to the increase of endothelin after acute myocardial infarction. Yasuda et al showed that concentrations of $\beta$ thromboglobulin and thrombinantithrombin III complex correlated with plasma endothelin concentration after infarction. ${ }^{7}$ It is also known that thrombin increases endothelin production in cultured endothelial cells. ${ }^{29}$ If activation of the clotting system were the primary cause of the rise in endothelin, higher concentrations would also have been expected in unstable angina, where platelets are activated and a thrombus forms within coronary arteries. ${ }^{3031}$ This was not the case in the present study, and Stewart et al have recently described normal concentrations of endothelin in coronary sinus plasma from patients with unstable angina. ${ }^{32}$ Similarly myocardial ischaemia and disruption of the coronary endothelium due to plaque rupture are unlikely to be principal causes as they too are common to both unstable angina and myocardial infarction. ${ }^{31}{ }^{33}$ Endothelin concentrations are raised in other situations of acute stress, such as major surgery, and may reflect a non-specific response. ${ }^{5}$ In keeping with this hypothesis Miyauchi et al have shown that the human pre-proendothelin-1 gene contains sequences related to the acute phase reactant response. ${ }^{8}$

Endothelin concentrations are known to rise on standing, presumably as a response to hypotension. ${ }^{34}$ Streptokinase induces hypotension in a proportion of patients but this is usually transient and whereas it is possible that it may have influenced endothelin levels at one hour it is unlikely to have a sustained effect. ${ }^{35}$ To ensure a homogenous population of patients with acute myocardial infarction only streptokinase treated patients were included in this study. We are therefore unable to comment on the influence of thrombolysis itself on concentrations of endothelin or atrial natriuretic factor. Reduced renal clearance of endothelin probably accounted at least in part for the high values in the patients with established cardiac failure, though other factors such as widespread endothelial dysfunction of the peripheral circulation cannot be ruled out. ${ }^{36}$ These mechanisms are unlikely to have been operative in our patients with myocardial infarction, none of whom had clinically evident cardiac failure.

The concentrations of plasma endothelin in our control group were similar to those reported by Davenport et al using the same assay. ${ }^{11}$ They are, however, considerably higher than those obtained by other assays, ${ }^{6-8}$ presumably as a result of differing cross reactivities of the antibodies used against the endothelin isopeptides and to big endothelin. These differences must be borne in mind when comparing our results with those of other workers.

We conclude that plasma concentrations of endothelin are raised within six hours of uncomplicated myocardial infarction. These values are probably not high enough to induce vasoconstriction alone but may do so in combination with other humoral factors. A number of mechanisms could contribute to this rise in endothelin but the exact cause remains uncertain.

Dr S Ray was supported by the British Heart Foundation.

1 Yanagisawa $\mathrm{M}$, Kurihara $\mathrm{H}$, Kimura S, et al. A novel poten vasoconstrictor peptide produced by vascular endothelia cells. Nature 1988;332:411-5.

2 Inoue A, Yanagisawa M, Kimura S, et al. The human endothelin family: Three structurally and pharmacologically distinct isopeptides predicted by three separate genes. Proc Natl Acad Sci USA 1989;86:2863-7.

3 Schichiri M, Hirata Y, Ando K, et al. Plasma endothelin levels in hypertension and chronic renal failure. Hypertension 1990;15:493-6.

4 Masaoka H, Suzuki R, Hirata Y, Emori T, Marumo F, Hirakawa $\mathrm{K}$. Raised plasma endothelin in aneurysma subarachnoid haemorrhage. Lancet 1989;ii:1402(letter).

5 Saito T, Yaganisawa M, Miyauchi T, et al. Endothelin in human circulating blood: Effects of major surgical stress [abstract]. Jpn J Pharmacol 1989;49:215.

6 Cernacek P, Stewart DJ. Immunoreactive endothelin in human plasma: Marked alterations in cardiogenic shock. Biochem Biophys Res Commun 1989;161:562-7.

7 Yasuda M, Kuhno M, Tahara A. Circulating immunoreactive endothelin in ischaemic heart disease. Am Heart $J$ tive endothelin in
1990;119:801-6.

8 Miyauchi T, Yanagisawa $M$, Tomizawa $T$. Increased plasma concentrations of endothelin-1 and big endothelin -1 in acute myocardial infarction. Lancet 1989;ii:53-4.

9 Salminen K, Takkanen I, Saijonmaa O, Nieminen $M$ Fyhrquist F, Frick MH. Modulation of coronary tone in acute myocardial infarction by endothelin. Lance 1989;ii:747.

10 Bonhomme M-C, Cantin M, Garcia R. Relaxing effect of atrial natriuretic factor on endothelin precontracted vascular strips. Proc Soc Exp Biol Med 1989;191:305-15.

11 Davenport AP, Ashby MJ, Easton P, et al. A sensitive radioimmunoassay measuring endothelin like immunoreactivity in human plasma: comparison of levels in patients with essential hypertension and normotensive control subjects. Clin Sci 1990;78:261-4.

12 Richards AM, Tonolo G, McIntyre GD, Leckie BJ, Robertson JIS. Radioimmunoassay for plasma alpha human atrial natriuretic peptide: A comparison of direct and preextracted methods. J Hyperten 1987;5:227-36.

13 O'Brien PC, Shampo MA. Statistical considerations for performing multiple tests in a single experiment. 5. 
Comparing two therapies with respect to several endpoints. Mayo Clin Proc 1988;63:1140-3.

14 Vierhapper $H$, Wagner $O$, Nowotny $P$, Waldhausl W. Effect of endothelin-1 in man. Circulation 1990;81:1415-8

15 Chester AH, Dashwood MR, Clarke JG. Influence of endothelin on human coronary arteries and localisation of its binding sites. Am J Cardiol 1989;63:1395-8.

16 Miyauchi T, Tomobe Y, Shiba R, et al. Involvement of endothelin in the regulation of human vascular tonus. Circulation 1990;81:1874-80.

17 Hughes AD, Thom A McG, Woodall N, et al. Human vascular responses to endothelin-1: observations in vivo vascular responses to endothelin-1: observations in vivo
and in vitro. J Cardiovasc Pharmacol 1989;13 (suppl 5):225-8.

18 Whittle BJR, Moncada S. The endothelin explosion. A pathophysiological reality or a biological curiosity. Circulation 1990;81:2022-5.

19 Yaganisawa M, Masaki T. Endothelin, a novel endothelium derived peptide. Biochemical Pharmacology 1989;38: 1877-83.

20 Wanatabe T, Suzuki N, Shimamato N, Fujino M, Imada A Endothelin in myocardial infarction. Nature 1990 344:144.

21 Ray SG, Leckie B, Findlay I, Raeside D, Northridge D, Dargie HJ. Changes in renin and atrial natriuretic during thrombolysis with streptokinase [abstract]. Eur Heart $J$ 1989;10:277.

22 Tan ACITL, Van Loenhout TT, Lamfers EJP, et al. Atrial natriuretic peptide after myocardial infarction. Am Heart J 1989;118:490-4.

23 Svanegaard J, Angelo-Nielsen K, Pindborg T. Atrial natriuretic peptide and acute myocardial infarction. $\mathrm{Am}$ Heart $J 1989 ; 117: 194-5$.

24 Fukuda Y, Hirata Y, Yoshimi H, et al. Endothelin is a poten secretagogue for atrial natriuretic peptide in cultured myocytes. Biochem Biophys Res Commun 1988;155: 167-72.

25 Stasch JP, Hirth-Dietrich C, Kazda S, Neuser D. Endothelin stimulates release of atrial natriuretic peptide in vitro and in vivo. Life Sci 1989;45:869-75.

26 Fyhrquist F, Saijonmaa O, Metsarinne K, Sirvio ML. Atria natriuretic peptide and nitroglycerine reduce endothelin secretion from cultured endothelial cells [abstract]. $\mathrm{Am}$ Hypertens 1990;3:90

27 Kohno M, Murakawa K, Yokokawa K, et al. Production of endothelin by cultured porcine endothelial cells: modulation by adrenaline. J Hypertens 1989;7 (suppl 6):130-1.

28 Yang Z, Richard V, von Segener L. Endothelin-1 potentiates contractions to nor-epinephrine and serotonin in human mammary and coronary arteries [abstract]. $\mathrm{J} \mathrm{Am} \mathrm{Coll}$ Cardiol 1990;15:12.

29 Emori T, Hirata Y, Ohta K, Schichiri M, Marumo F. Secretory mechanism of immunoreactive endothelin in cultured bovine endothelial cells. Biochem Biophys Res cultured bovine endothel

30 Fitzgerald DJ, Roy L, Catella F, Fitzgerald GA. Platelet Fitzgerald DJ, Roy L, Catella F, Fitzgerald GA. Platelet
activation in unstable coronary disease. $N$ Engl J Med 1986;315:983.

31 Sherman CT, Litvack F, Grundfest W, et al. Coronary angioscopy in patients with unstable angina. $N \mathrm{Eng} J \mathrm{Med}$ 1986;315:913-9.

32 Stewart JT, Nisbet JA, Davies MJ. Plasma endothelin in coronary venous blood from patients with either stable or unstable angina. Br Heart $J$ 1991;66:7-9.

33 Davies MJ, Thomas A. Thrombosis and acute coronary artery lesions in sudden cardiac ischaemic death. $N$ Eng $J$ artery lesions in sudden

34 Schichiri M, Hirata Y, Ando K. Postural change and volume expansion affect plasma endothelin levels. JAMA expansion af

35 Lew AS, Laramee P, Cercek B, Shah P, Ganz W. The hypotensive effect of intravenous streptokinase in patients with acute myocardial infarction. Circulation 1985 72:1321-6.

36 Kohno M, Murukawa K, Yasunari K, et al. Prolonged blood pressure elevation after endothelin administration in bilaterally nephrectomised rats. Metabolism 1989;38 712-3. 